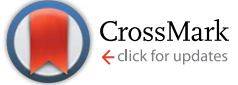

Cite this: RSC Adv., 2017, 7, 9051
Received 21st November 2016 Accepted 25th January 2017

DOI: $10.1039 / \mathrm{c} 6 \mathrm{ra} 27124 \mathrm{c}$

rsc.li/rsc-advances

\section{High-flux underwater superoleophobic hybrid membranes for effective oil-water separation from oil-contaminated water}

\author{
Minxiang Zeng, ${ }^{a}$ Baoliang Peng, ${ }^{\text {bc }}$ Carlos Ybanez, ${ }^{a}$ Nian Wei Tan, ${ }^{d}$ Ehab Abo Deeb, \\ Eric Bordovsky, ${ }^{a}$ Chang-Hyun Choi, ${ }^{a}$ Ian Echols, ${ }^{a}$ Andrew Nguyen, ${ }^{a}$ Alan Ye, ${ }^{d}$ \\ Nutchapol Dendumrongsup, ${ }^{d}$ Lecheng Zhang, ${ }^{a}$ Dali Huang, ${ }^{f}$ Pingmei Wang, ${ }^{\text {bc }}$ \\ Jianhui Luo, ${ }^{\text {bc }}$ Yue Situ ${ }^{\text {ag }}$ and Zhengdong Cheng*afh
}

\begin{abstract}
Recent oil spills and the rapid expansion of petrochemical industries have highlighted the challenge of effective oil-water separation. Developing a filtration platform based on new surface modification strategies that exhibits good oil-water separation, particularly in a complex environment, is highly desirable for purposes of environmental clean-up. Herein, we present a polymer-modified filter paper (PMFP) with an underwater superoleophobic surface fabricated via a facile dip-coating process. The asprepared polymer-modified filter paper not only separates the oil-water mixture in gentle environment, but performs effectively in harsh environments, including high salt concentrations, extreme $\mathrm{pH}$, and oilin-water emulsions with surfactants, suggesting its great potential for large-scale industrial applications.
\end{abstract}

\section{Introduction}

Oil contaminated wastewater from petrochemical industries and oil spills has been plaguing the earth for decades by causing serious environmental issues. ${ }^{\mathbf{1} 2}$ For example, polycyclic aromatic hydrocarbons and other oily chemicals in wastewater pose a potential risk to aquatic ecosystems as their decomposition causes excessive oxygen consumption, which leads to an increased mortality rate in fish populations. ${ }^{3}$ Therefore, the challenge of effective oil-water separation has been highlighted. Conventional oil-water separation methods, including gravity separation, air flotation, coagulation, and deemulsification, have inherent disadvantages such as low

${ }^{a}$ Artie McFerrin Department of Chemical Engineering, Texas A \& $M$ University, College Station, TX 77843, USA

${ }^{b}$ Research Institute of Petroleum Exploration \& Development (RIPED), PetroChina, Beijing 100083, China

'Key Laboratory of Nano Chemistry (KLNC), CNPC, Beijing 100083, China

${ }^{d}$ Harold Vance Department of Petroleum Engineering, Texas A \& M University, College Station, TX 77843, USA

${ }^{e}$ Zachry Department of Civil Engineering, Texas A \& M University, College Station, TX 77843, USA

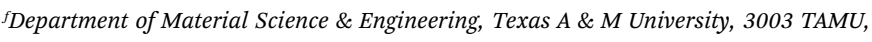
College Station, TX 77843, USA

${ }^{8}$ School of Chemistry and Chemical Engineering, South China University of Technology, Guangzhou 510640, P. R. China

${ }^{h}$ Professional Program in Biotechnology, Texas A \& M University, TX 77843, USA. E-mail: zcheng@tamu.edu; Fax: +1-979-845-6446; Tel: +1-979-845-3413

$\dagger$ Electronic supplementary information (ESI) available: See DOI: $10.1039 / \mathrm{c} 6 \mathrm{ra} 27124 \mathrm{c}$ efficiency, high energy consumption, and recontamination problems. ${ }^{4-7}$ Separation of oil and water is essentially an interfacial science problem, and thus new strategies based on unique wettability materials have shown to be effective and advantageous. ${ }^{8,9}$

Materials with surface-active features, such as superhydrophilic or hydrophobic coating, have attracted great attention. $^{8-18}$ By carefully controlling surface chemistry and morphology, fabric, ${ }^{19-22}$ mesh, ${ }^{23-26}$ foam, ${ }^{27}$ and polymeric membrane ${ }^{28-31}$ have been fabricated with special wettabilities that enable successful separation of oil and water from oilwater mixture. Recently, Shang and co-workers reported the fabrication of superhydrophobic nanofibrous membranes by electrospinning cellulose acetate nanofibers with an in situ polymerization approach. The as-prepared membranes can selectively and effectively separate oil from oil-water mixtures with good stability over a wide $\mathrm{pH}$ range. In addition to electrospinning, superwetting materials have also been fabricated by etching, ${ }^{32}$ nanoimprint lithography, ${ }^{33}$ sol-gel process, ${ }^{34}$ phase separation, ${ }^{35}$ and dip-coating. ${ }^{\mathbf{8 , 9 3 6}}$ In particular, dipcoating of filter paper has attracted interest due to good processability, low cost, and eco-friendly features. In 2016, Fragouli et al. developed a superoleophobic filter paper by a two-step dip adsorption process. ${ }^{9}$ The modified filter papers are mechanically reinforced, exhibiting good oil-water separation efficiency for non-stabilized emulsions. Despite some reported studies on coating filter papers, however a comprehensive study of separation behaviors under harsh conditions, such as extreme temperature, is absent, and new surface modification strategies are still desirable. 
Herein, we propose a hydrogel-coated superoleophobic filter paper for efficient oil-water separation in complex environments. Taking advantage of the high reactivity of crosslinker tolylene diisocyanate (TDI) with hydroxyl group, ${ }^{37}$ we demonstrate that poly vinyl alcohol (PVA) and filter paper can be covalently bonded into a superoleophobic network. For the first time, TDI-based polymer-modified filter paper (PMFP) was proven to separate oil and water successfully, and exhibited excellent oil-water separation efficiency up to $99.2 \%$. Meanwhile, the PMFP also reveals good tolerance to highly acidic, alkaline, and salty environments and a wide range of temperature, making it applicable to practical applications.

\section{Experimental}

\section{Materials}

PVA $\left(M_{\mathrm{w}}=85000-124000,99 \%\right.$ hydrolyzed), polyethylene glycol $\left(M_{\mathrm{w}}=20000,98 \%\right)$, toluene $(99.5 \%)$, heptane $(99 \%)$, sodium hydroxide (97\%) and sodium dodecyl sulfate (98\%) were purchased from Sigma-Aldrich (USA). Tolylene diisocyanate (98\%) was obtained from TCI America (USA). Hydrochloric acid solution (37\% in water), ethyl acetate (99.5\%) and hexanes (99\%) were obtained from Fisher Chemical (USA). Sodium chloride was obtained from Avantor Performance Materials (USA). Carbon tetrachloride (99.5\%), cetyltrimethylammonium bromide (99\%) and dichloromethane (98\%) were purchased from Acros Organics (USA). Crude oil was obtained from Texas Crude Corporation (USA). Filter papers with particle retention size $\approx 25 \mu \mathrm{m}$ were obtained from Fisher Scientific Corporation (USA, 09-790-12D). All chemicals used for the experiments were of standard commercial grade, and were used as received without further purification.

\section{Preparation of polymer-modified filter papers}

The polymer-modified filter paper was fabricated by a crosslinking reaction between PVA and the cellulose network of filter papers where TDI was used as a cross-linker, as shown in Fig. 1. In a typical procedure, the pristine filter papers were first immersed in $4 \mathrm{wt} \%$ PVA aqueous solution for $0.5 \mathrm{~h}$ at ambient temperature. Then, the PVA-treated filter papers were dried thoroughly in an oven at $65{ }^{\circ} \mathrm{C}$ for $12 \mathrm{~h}$ to remove potential

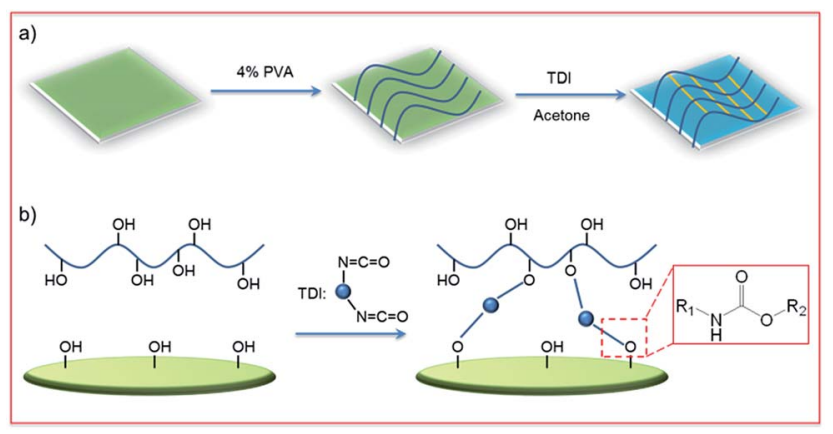

Fig. 1 (a) Schematic of dip-coating fabrication of polymer-modified filter papers. (b) Illustration of the crosslinking reaction between hydroxyl groups $-\mathrm{OH}$ and isocyanate groups of TDI. surface moisture. Next, $1 \mathrm{~mL}$ of TDI solution $(0.1 \mathrm{v} / \mathrm{v} \%$ in anhydrous acetone) was applied on the dried PVA-treated filter paper, allowing the crosslinking process for $24 \mathrm{~h}$ at room temperature. Finally, the obtained PVA-coated filter paper was washed with deionized water and acetone several times to remove potential excess PVA or byproducts before use.

\section{Contact angle measurement}

Oil droplets (dichloromethane dyed with Sudan IV, approximately $5 \mu \mathrm{L}$ ) were dropped onto the polymer-modified filter paper under water and allowed to equilibrate for $20 \mathrm{~s}$ before making any measurement. To evaluate underwater contact angles under acidic, alkaline, and saline conditions, we used $0.1 \mathrm{M} \mathrm{HCl}$ solution, $0.1 \mathrm{M} \mathrm{NaOH}$ solution, and $0.1 \mathrm{M} \mathrm{NaCl}$ solution as the aqueous phase respectively. A digital camera was used to record the images which were then analyzed by the software package, ImageJ. The mean values of three measurements performed on the same sample were adopted as the contact angles.

\section{Evaluation of oil-water separation efficiency}

The separation efficiency was examined by measuring the oil concentration in separated aqueous phase. The oil-water mixtures were carefully poured onto polymer-modified membranes under different conditions where the volume fraction of oil in mixture was fixed at $20 \mathrm{v} / \mathrm{v} \%$. A series of oils/ organic solvents, including heptane, toluene, ethyl acetate, and crude oil, were used in this experiment. For experiments under different temperature, the oil, water, and separation setup were precooled or preheated to desired temperature before measurements. After the completion of separation, the oil content of the collected water was measured by an infrared spectrometer. Specifically, carbon tetrachloride $\left(\mathrm{CCl}_{4}\right)$ was used to extract oils from water, followed by a measurement of absorbance at $2930 \mathrm{~cm}^{-1}$, as shown in Fig. S1. $\dagger$ The oil content of each sample was acquired by calculating the absorbance and the correction coefficient (Fig. S2 ESI†).

\section{Evaluation of flux performance}

The fluxes were calculated by measuring the time for flowing constant volume of feed solutions from the known area of the PMFP. The height of the feed solution was fixed at $7 \mathrm{~cm}$ by using a glass tube with an outlet to drain excess solution. $0.1 \mathrm{M} \mathrm{HCl}$ solution, 0.1 M NaOH solution, 0.1 M NaCl solution, and deionized water were used to simulate acidic, alkaline, saline, and neutral conditions, in which we measured $20 \mathrm{~mL}$ of collected solution for each condition.

\section{Characterization}

The surface chemistry of PMFP was determined by X-ray photoelectron spectroscopy (XPS) analysis on an Omicron's DAR 400 using $\mathrm{Mg} \mathrm{K} \alpha$ radiation as the excitation source. The binding energies were referenced to $\mathrm{C} 1 \mathrm{~s}$ at $284.80 \mathrm{eV}$. Fourier transform infrared spectroscopy (FTIR) was recorded on a Thermo Nicolet 380 FTIR spectrometer to evaluate oil content. 
Scanning electron microscopy (SEM) images of pristine filter paper and PMFP were obtained using a field emission scanning electron microscope (JEOL JSM-7500F, Japan). Samples were coated with $5 \mathrm{~nm}$ palladium/platinum $(20 \% \mathrm{Pd}$ and $80 \% \mathrm{Pt})$ prior to SEM imaging.

\section{Results and discussion}

\section{Surface chemistry of PMFP}

The polymer-modified filter papers were fabricated by a crosslinking reaction between PVA and the cellulose network of filter papers using TDI as a cross-linker. As shown in Fig. 1a, the pristine filter paper was first treated with PVA, followed by the addition of the TDI solution in acetone. In the first step, the hydroxyl groups of cellulose interacted with PVA only through physical adsorption, such as hydrogen bonding, while a chemically covalent bond had yet to be formed. After adding TDI as the crosslinker, the cellulose network was able to connect with PVA covalently by reacting - $\mathrm{OH}$ with the isocyanate groups (Fig. 1b). This procedure of fabricating polymer-modified filter paper is straightforward and economically efficient, allowing for scale-up production.

To investigate the surface chemistry of modified filter papers, high resolution $\mathrm{C} 1 \mathrm{~s}, \mathrm{O} 1 \mathrm{~s}$ and $\mathrm{N}$ 1s XPS spectra were collected. As shown in Fig. 2, the characteristic peaks of binding energy at $284.7,288.9,397.8,407.5$, and $531.3 \mathrm{eV}$ were found, which can be assigned to the $\mathrm{C} 1 \mathrm{~s}$ of $\mathrm{C}-\mathrm{C}$ bonds, the $\mathrm{C} 1 \mathrm{~s}$ of $\mathrm{O}=\mathrm{C}-\mathrm{O}$ bonds, the $\mathrm{N} 1 \mathrm{~s}$ of $\mathrm{C}-\mathrm{N}-\mathrm{H}$ bonds, the $\mathrm{N} 1 \mathrm{~s}$ of $\mathrm{C}-\mathrm{N}-\mathrm{O}$ bonds, and the $\mathrm{O} 1 \mathrm{~s}$ of $\mathrm{C}-\mathrm{O}$ bonds in ethers and hydroxyls, respectively. Elemental analysis of the polymer-modified filter paper was also carried out, revealing a $\mathrm{C}: \mathrm{O}: \mathrm{N}$ atomic ratio of $90: 26: 1$. These results indicated the solid crosslink between PVA and filter paper by TDI. ${ }^{38,39}$

\section{Morphology characterization}

The morphologies of pristine and polymer-modified filter papers were examined by FE-SEM. As displayed in Fig. 3a, the pristine filter paper shows a porous surface with average pore size around $25 \mu \mathrm{m}$. The high magnification of the SEM image (Fig. 3b) reveals a coarse surface with randomly aligned cellulose fibers. Fig. $3 c$ and d reflects the morphologies of filter papers after the crosslinking processes with PVA and TDI. As shown in Fig. 3c, the porous structure still remains with a similar average pore size. After the crosslinking process, however, the original cellulose fiber becomes completely
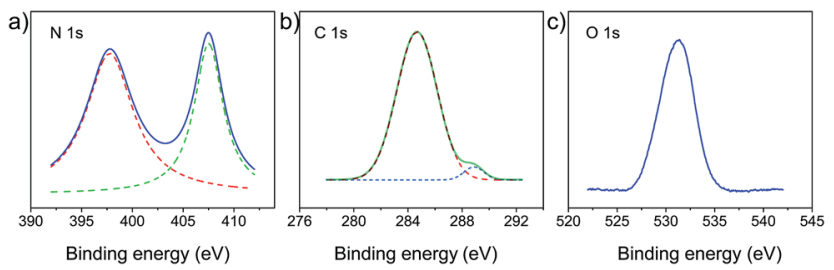

Fig. 2 XPS of PMFP (a) high-resolution $N$ 1s spectrum of PMFP. (b) High-resolution C 1s XPS spectrum of PMFP. (c) High-resolution $O$ 1s XPS spectrum of PMFP.
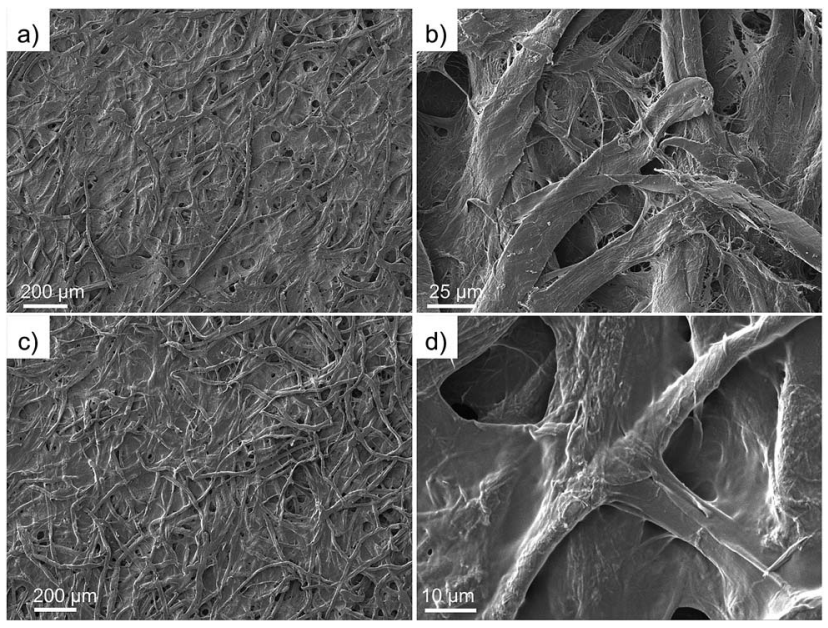

Fig. 3 The morphologies of filter papers. (a) SEM images of the pristine filter paper. (b) SEM images of the pristine filter paper with high magnifications. (c) SEM images of the polymer-modified filter paper. (d) SEM images of the polymer-modified filter paper with high magnifications.

covered by a dense and uniform layer of polymer at the microscale, as shown in Fig. 3d. The as-prepared polymer-modified filter paper reveals a smoother structure, indicating that functionalization of PVA induces a significant change in morphologies. The decrease in surface roughness of polymer-modified filter paper further demonstrates that PVA is successfully coated on the cellulose fiber of the filter paper.

\section{Wettability performance}

To demonstrate the oil-water separation capacity of PMFP, we studied the wettability of as-prepared filter paper by measuring underwater contact angles of oil droplets. Generally, the more oleophobic a surface is, the larger a contact angle with oil we could expect. In particular, surfaces are called superoleophobic if showing a contact angle $\theta$ greater than $150^{\circ}$ for organic liquids. ${ }^{40}$ As shown in Fig. 4a, nearly no loss of the oil droplet was observed upon contacting with polymer-modified filter paper, indicating low affinity of PMFP for oil. According to the
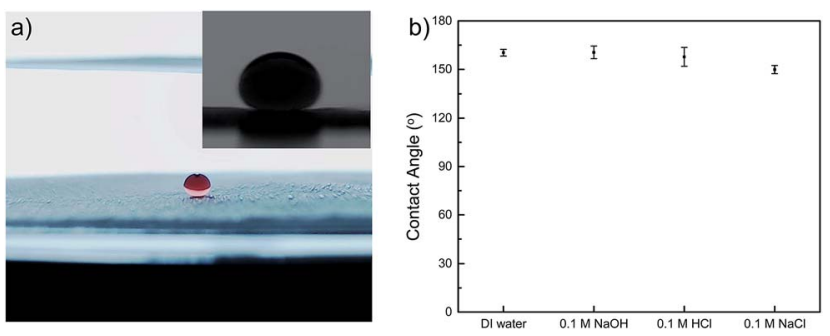

Fig. 4 Wettability and contact angles of polymer-modified filter papers. (a) Photographic images of underwater superoleophobic property of PMFP (inset: underwater contact angle measurement of oil droplets). (b) Contact angles of PMFP under in acidic, alkaline, saline, and neutral environments, exclusively showing large contact angles $\left(>150^{\circ}\right)$. 
contact angle measurements, the PMFP presented underwater superoleophobicity with an oil contact angle of $160.3 \pm 2.1^{\circ}$. Acidic, alkaline, and saline conditions were also examined, exclusively showing large contact angles, as shown in Fig. 4 b. These results suggested that the affinity of PMFP for oil droplets is negligible. This can be explained by water molecules becoming trapped in the porous hydrophilic structures so that the oil droplets are repelled from the surface of hydrogel-coated filter paper when the polymer modified filter paper is immersed in water. ${ }^{8}$

\section{Oil-water separation}

Separation of oil and water was carried out by directly pouring the oil-water mixture into the filter paper supported by a glass funnel. Heptane was used as the oil phase and the volume fraction of heptane in mixture was fixed at $20 \mathrm{v} / \mathrm{v} \%$. The temperature effect on oil-water separation efficiency of PMFP was first examined. At low temperature $\left(2{ }^{\circ} \mathrm{C}\right)$, room temperature $\left(20^{\circ} \mathrm{C}\right)$, and high temperature $\left(65^{\circ} \mathrm{C}\right)$, water permeated easily, while the heptane was retained above the modified filter paper. No visible oil was observed in the separated water, suggesting good oil-water separation capacity of PMFP. As shown in Fig. 5a, the separation efficiency of all cases was measured to be $>98 \%$, which is comparable to those reported in literature. $^{12,13,17}$ This indicates that the oil-water separation capacity of PMFP will not be strongly influenced by the temperature in the range of $2{ }^{\circ} \mathrm{C}$ to $65^{\circ} \mathrm{C}$.

To investigate the performance of filter paper under saline conditions, we used brine solutions as aqueous phases to test oil-water separation efficiency. Under different salinity, polymer-modified filter paper show high efficiency $(>98 \%)$ as shown in Fig. 5b, indicating strong resistance of modified filter
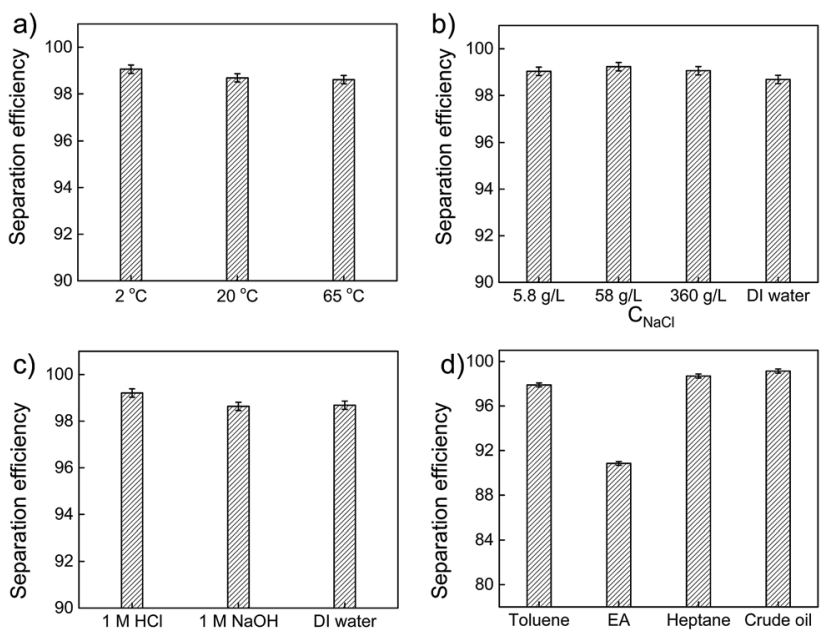

Fig. 5 Oil-water separation efficiencies of PMFP under different conditions. (a) The separation efficiency of PMFP for separating heptane-water mixtures $(20: 80 \mathrm{v} / \mathrm{v})$ at different temperature. (b) Separation efficiency of heptane-brine mixtures $(20: 80 \mathrm{v} / \mathrm{v})$. (c) The separation efficiency in acidic, alkaline, and neutral environment. (d) The separation efficiency of various types of oil-in-water emulsions containing $0.5 \mathrm{wt} \% \mathrm{SDS}$. paper to high-salinity environments. It is worth noting that polymer-modified filter papers show good tolerance with a high $\mathrm{NaCl}$ concentration of $360 \mathrm{~g} \mathrm{~L}^{-1}$ (Fig. 5b) which is greater than ten times higher than the salinity of seawater $\left(\sim 35 \mathrm{~g} \mathrm{~L}^{-1}\right),{ }^{41}$ suggesting great potential of PMFP for application in oilseawater separation under typical conditions of offshore locations. The oil-water separation capacity under extreme $\mathrm{pH}$ was also investigated. We used $1 \mathrm{M} \mathrm{HCl}$ solution and $1 \mathrm{M} \mathrm{NaOH}$ solution as aqueous phases while deionized water was used for reference. As shown in Fig. 5c, the oil-water mixtures were successfully separated with high efficiency ( $>98 \%$ ), indicating good tolerance of filter paper for acidic and alkaline environments. This high stability of filter paper in acid, alkali and salty water can be attributed to the formation of multiple robust covalent bonds among a crosslinked cellulose network.

Given that wastewater often contains a rich variety of hydrophobic compounds, we examined the capacity of polymermodified filter paper with different type of oils, including heptane, toluene, ethyl acetate, and crude oil. Those four types of oils are representative: heptane is a hydrophobic long-chain alkane; toluene is aromatic; ethyl acetate is very polar with slight solubility in water whereas crude oil is a very complex mixture of hydrophobic molecules. Owing to the common existence of surfactants in waste water, we simulate oil-water separation by using aqueous phases in presence of $0.5 \mathrm{wt} \%$ sodium dodecyl sulfonate (SDS). To ensure the formation of stable emulsions, the samples were emulsified by mixing $0.5 \mathrm{wt} \%$ SDS solution and different types of oils using a homogenizer at 1000 rpm. As shown in Fig. 5d, the separation efficiencies of SDS/ heptane $/ \mathrm{H}_{2} \mathrm{O}$, SDS/toluene $/ \mathrm{H}_{2} \mathrm{O}$, SDS/ethyl acetate $/ \mathrm{H}_{2} \mathrm{O}$, and SDS/ crude oil $/ \mathrm{H}_{2} \mathrm{O}$ were obtained. It is worth noting that the separation efficiencies are excellent for heptane, toluene, and crude oil emulsions but moderate separation (91\%) is observed in ethyl acetate emulsions. Although no visible oil was observed to permeate from the upper emulsions to the collected water phase, the separation efficiency was measured to be just above $90 \%$. This suggests that there is around $10 \%$ ethyl acetate remaining in the collected water phase, probably as a solute form instead of an immiscible droplet form. The solubility of ethyl acetate is $8.42 \mathrm{~g}$ in $100 \mathrm{~g}$ water at $20{ }^{\circ} \mathrm{C}$, which is quite consistent with our observation ( $\sim 9 \%$ ethyl acetate in collected water).$^{\mathbf{4 2}}$

To further explore the separation capacity of polymermodified filter paper, three types of surfactant-stabilized heptane-in-water emulsions were employed. Those surfactants include anionic sodium dodecyl sulfonate, cationic cetyltrimethylammonium bromide (CTAB), and nonionic polyethylene glycol (PEG). As shown in Fig. 6a-c, the microscopic images demonstrated the size distribution of heptane droplets in various surfactant-stabilized aqueous solutions, showing that the droplet diameters varied from $2 \mu \mathrm{m}$ to $50 \mu \mathrm{m}$. The PMFP was then used to separate water from surfactant-stabilized oil-inwater emulsions, as shown in Fig. 6d. Despite the huge difference of droplet sizes among different surfactant-stabilized emulsions, the oil-water separation efficiency are consistently high $(>98 \%)$ with no visible oil droplets remaining in the collected water. The results indicate strong potential of PMFP for practical application in complex environments. 
a)

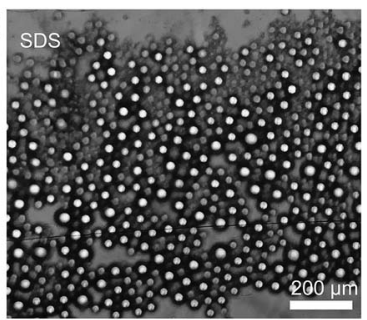

c)

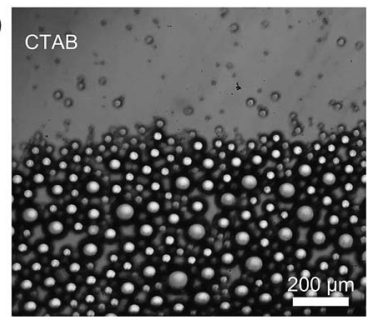

b)

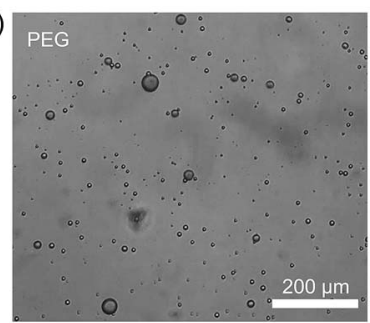

d)

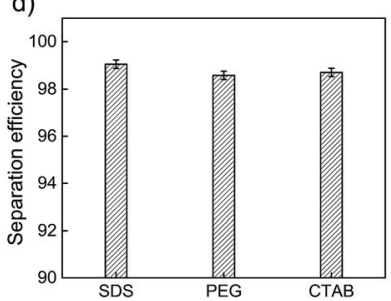

Fig. 6 Oil-water separation efficiencies of PMFP with various oils. (ac) The microscopic images of heptane-in-water emulsions containing (a) SDS, (b) PEG, and (c) CTAB. (d) Separation efficiency of various types of surfactant-stabilized heptane-in-water emulsions containing 20 vol\% heptane.

\section{Flux performance}

As a very important parameter for oil-in-water emulsion separation, the flux of various aqueous phases that permeate through the PMFP was also measured. The fluxes were obtained by calculating the time for flowing constant volume of feed solutions from the valid area of the membrane while keeping the height of the feed solution constantly at $7 \mathrm{~cm}$, as shown in Fig. 7a. We used a glass tube with an outlet to ensure the constant height of tested solutions. In general, all permeates exhibit high fluxes and deionized water possesses higher fluxes than $0.1 \mathrm{M} \mathrm{HCl}$ solution, $0.1 \mathrm{M} \mathrm{NaOH}$ solution, and $0.1 \mathrm{M} \mathrm{NaCl}$ solution. To be specific, as shown in Fig. 7b, fluxes of $4380 \pm$ $184,3898 \pm 48,3091 \pm 235$, and $3020 \pm 50 \mathrm{~L} \mathrm{~m}^{-2} \mathrm{~h}^{-1}$ are obtained for deionized, $0.1 \mathrm{M} \mathrm{HCl}$ solution, $0.1 \mathrm{M} \mathrm{NaOH}$ solution, and $0.1 \mathrm{M} \mathrm{NaCl}$ solution, respectively. Those fluxes of polymermodified filter papers are comparable to that of high flux pol$\mathrm{y}$ (vinylidene fluoride) (PVDF) membrane. ${ }^{43}$ The flux difference among various aqueous samples can be contributed to the viscosity difference as the flux is inversely proportional to the liquid viscosity, and potential swelling effect on the polymer
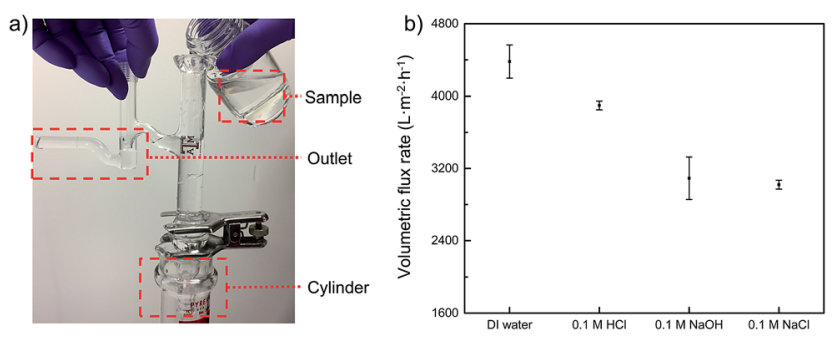

Fig. 7 (a) Photographic illustration of flux measurement. (b) Volumetric flux rates of PMFP under in acidic, alkaline, saline, and neutral environments.

network of PVA under different $\mathrm{pH}$ which induces a change in pore size. ${ }^{37,44}$ For acidic, alkaline, saline solutions, the volumetric flux is in the range of $3000-3900 \mathrm{~L} \mathrm{~m}^{-2} \mathrm{~h}^{-1}$. Although these values are smaller than that of deionized water, they are still considerably high compared to those of commercial filtration membranes, such as an ultrafiltration membrane with similar permeation properties, and which usually gives a flux of less than $300 \mathrm{~L}$ per $\mathrm{m}^{2}$ per $\mathrm{h}$ per bar. ${ }^{43,45-47}$ Moreover, given that no external pressure was employed in our experiment and the permeation was driven solely by gravity, it is possible that further improvement on volumetric flux of PMFP can be achieved.

The overall results indicate that polymer-modified filter papers not only demonstrate strong potential in oil-water separation for a wide range of conditions, such as high salt concentrations, extreme $\mathrm{pH}$, different temperatures, and oilwater emulsions stabilized by a variety of surfactants, but also show high flux in acidic, alkaline, saline environments. Further research is still desirable to design and build surface-active filter systems to sophisticatedly control the oil-water separation process.

\section{Conclusions}

In conclusion, we demonstrated a successful modification of the filter paper by using polyvinyl alcohol and tolylene diisocyanate, leading to an underwater superoleophobic surface with oil contact angle larger than $160^{\circ}$. SEM analysis revealed morphology change after modification, while the porosity of filter paper was not altered significantly. Owing to the good stability and robust structure of crosslinked networks, the modified filter paper not only separates oil-water mixture in harsh environments, such as high salt concentrations, extreme $\mathrm{pH}$, and different temperature $\left(2-65^{\circ} \mathrm{C}\right)$, but it also shows good separation efficiency for oil-water emulsions stabilized by different surfactants. Various oils have been tested based on their water emulsions and the superoleophobic filter paper possesses excellent oil-water separation efficiency (up to 99.2\%) with high flux. This approach is straightforward and easy to scale-up, opening a pathway for the fabrication of novel superwetting materials.

\section{Acknowledgements}

The authors would like to acknowledge partial financial support from the Aggie Challenge program, NASA (NASA-NNX13AQ60G) and China National Petroleum \& Gas Corporation Science and Technology Development Project "Study on Asymmetric Modification Methods for Nanoplatelet Particles" (405550). The authors thank Prof. Lagoudas for useful discussion and the Materials Characterization Facility (MCF) at Texas A \& M University for access to FTIR and XPS.

\section{Notes and references}

1 E. Kintisch, Science, 2010, 329, 735-736. 
2 M. A. Shannon, P. W. Bohn, M. Elimelech, J. G. Georgiadis, B. J. Marinas and A. M. Mayes, Nature, 2008, 452, 301-310.

3 D. Connell, G. Miller and J. Farrington, Crit. Rev. Environ. Sci. Technol., 1981, 11, 105-162.

4 M. Cheryan and N. Rajagopalan, J. Membr. Sci., 1998, 151, 13-28.

5 T. Krebs, C. Schroën and R. Boom, Chem. Eng. Sci., 2012, 71, 118-125.

6 Y. Zeng, C. Yang, J. Zhang and W. Pu, J. Hazard. Mater., 2007, 147, 991-996.

7 Y. Xuan, J. Peng, L. Cui, H. Wang, B. Li and Y. Han, Macromolecules, 2004, 37, 7301-7307.

8 J. B. Fan, Y. Song, S. Wang, J. Meng, G. Yang, X. Guo, L. Feng and L. Jiang, Adv. Funct. Mater., 2015, 25, 5368-5375.

9 U. C. Paul, D. Fragouli, I. S. Bayer and A. Athanassiou, Polymers, 2016, 8, 52.

10 L. Zhang, Z. Zhang and P. Wang, NPG Asia Mater., 2012, 4, e8. 11 S. H. Wang, M. Li and Q. H. Lu, ACS Appl. Mater. Interfaces, 2010, 2, 677-683.

12 J. Zhu, H. Li, J. Du, W. Ren, P. Guo, S. Xu and J. Wang, J. Appl. Polym. Sci., 2015, 132, 1-5.

13 J. Ju, T. Wang and Q. Wang, J. Appl. Polym. Sci., 2015, 132, 1-7. 14 Y.-H. Yu, Y.-P. Chen, M. Zeng and Z. Cheng, Mater. Lett., 2016, 163, 158-161.

15 M. Zeng, X. Wang, Y.-H. Yu, L. Zhang, W. Shafi, X. Huang and Z. Cheng, J. Nanomater., 2016, 2016, 1-8.

16 X. Z. Wang, L. C. Zhang, Y. H. Yu, L. S. Jia, M. S. Mannan, Y. Chen and Z. D. Cheng, Sci. Rep., 2015, 5, 13357.

17 J. Wang and Y. Chen, J. Appl. Polym. Sci., 2015, 132, 1-6.

18 Y. Wang, Y. Shi, L. Pan, M. Yang, L. Peng, S. Zong, Y. Shi and G. Yu, Nano Lett., 2014, 14, 4803-4809.

19 W. Ma, Q. Zhang, D. Hua, R. Xiong, J. Zhao, W. Rao, S. Huang, X. Zhan, F. Chen and C. Huang, RSC Adv., 2016, 6, 12868-12884.

20 Y. W. Liu, C. H. Zhang, Z. Q. Wang, X. Fu and R. Wei, RSC Adv., 2016, 6, 87332-87340.

21 X. Zhou, Z. Zhang, X. Xu, F. Guo, X. Zhu, X. Men and B. Ge, ACS Appl. Mater. Interfaces, 2013, 5, 7208-7214.

22 B. Wang, J. Li, G. Wang, W. Liang, Y. Zhang, L. Shi, Z. Guo and W. Liu, ACS Appl. Mater. Interfaces, 2013, 5, 1827-1839.

23 J. Li, D. Li, Y. Yang, J. Li, F. Zha and Z. Lei, Green Chem., 2016, 18, 541-549.

24 Z. Xue, S. Wang, L. Lin, L. Chen, M. Liu, L. Feng and L. Jiang, Adv. Mater., 2011, 23, 4270-4273.

25 Y. Cao, X. Zhang, L. Tao, K. Li, Z. Xue, L. Feng and Y. Wei, ACS Appl. Mater. Interfaces, 2013, 5, 4438-4442.
26 F. Zhang, W. B. Zhang, Z. Shi, D. Wang, J. Jin and L. Jiang, Adv. Mater., 2013, 25, 4192-4198.

27 Z.-Y. Luo, K.-X. Chen, J.-H. Wang, D.-C. Mo and S.-S. Lyu, J. Mater. Chem. A, 2016, 4, 10566-10574.

28 C.-T. Liu and Y.-L. Liu, J. Mater. Chem. A, 2016, 4, 1354313548.

29 W. Zhang, X. Lu, Z. Xin and C. Zhou, Nanoscale, 2015, 7, 19476-19483.

30 J. Zhang and S. Seeger, Adv. Funct. Mater., 2011, 21, 46994704.

31 W. Zhang, Y. Zhu, X. Liu, D. Wang, J. Li, L. Jiang and J. Jin, Angew. Chem., Int. Ed., 2014, 53, 856-860.

32 S. E. Lee, H.-J. Kim, S.-H. Lee and D.-G. Choi, Langmuir, 2013, 29, 8070-8075.

33 H.-J. Choi, S. Choo, J.-H. Shin, K.-I. Kim and H. Lee, J. Phys. Chem. C, 2013, 117, 24354-24359.

34 S. S. Latthe, C. Terashima, K. Nakata, M. Sakai and A. Fujishima, J. Mater. Chem. A, 2014, 2, 5548-5553.

35 S. Aruna, P. Binsy, E. Richard and B. J. Basu, Appl. Surf. Sci., 2012, 258, 3202-3207.

36 L. Yao and J. He, J. Mater. Chem. A, 2014, 2, 6994-7003.

37 B. Bolto, T. Tran, M. Hoang and Z. Xie, Prog. Polym. Sci., 2009, 34, 969-981.

38 S. Bonakdar, S. H. Emami, M. A. Shokrgozar, A. Farhadi, S. A. H. Ahmadi and A. Amanzadeh, Mater. Sci. Eng., C, 2010, 30, 636-643.

39 Z. Gao, J. Gu, X. Wang, Z. Li and X. Bai, Pigm. Resin Technol., 2005, 34, 282-289.

40 X. Deng, L. Mammen, H.-J. Butt and D. Vollmer, Science, 2012, 335, 67-70.

41 Y. Tanaka, M. Reig, S. Casas, C. Aladjem and J. L. Cortina, Desalination, 2015, 367, 76-89.

42 A. Altshuller and H. Everson, J. Am. Chem. Soc., 1953, 75, 1727.

43 W. Zhang, Z. Shi, F. Zhang, X. Liu, J. Jin and L. Jiang, Adv. Mater., 2013, 25, 2071-2076.

44 S. M. M. Quintero, M. Cremona, A. Triques, A. d'Almeida and A. Braga, Polymer, 2010, 51, 953-958.

45 H.-J. Li, Y.-M. Cao, J.-J. Qin, X.-M. Jie, T.-H. Wang, J.-H. Liu and Q. Yuan, J. Membr. Sci., 2006, 279, 328-335.

46 A. Lobo, Á. Cambiella, J. M. Benito, C. Pazos and J. Coca, J. Membr. Sci., 2006, 278, 328-334.

47 G. Gutiérrez, A. Lobo, J. M. Benito, J. Coca and C. Pazos, J. Hazard. Mater., 2011, 185, 1569-1574. 